\section{Prevalence of violent victimisation in severe}

\section{mental illness}

\author{
ELIZABETH WALSH, PAUL MORAN, CHARLES SCOTT, KWAME McKENZIE, \\ TOM BURNS, FR ANCIS CREED, PETER TYRER, * ROBIN. M. MURR AY and \\ TOM FAHY on behalf of the UK700 GROUP
}

Since de-institutionalisation, much has been written about the risk posed to members of the public by those with severe mental illness (Mullen et al, 2000). The overall evidence, however, is that the contribution made by those with psychosis to violent crime in society is small and is accounted for by a small minority of patients (Walsh et al, 2002). Conversely, little attention generally is paid to the risk posed to this vulnerable group of people. Cross-sectional surveys have reported the prevalence of criminal victimisation to be high among mentally ill people (Hiday et al, 1999; Brekke et al, 2001; Hiday et al, 2002). The only case-control study to date has found those with severe mental illness at significantly increased risk of violent victimisation compared with neighbourhood controls, after controlling for socioeconomic disadvantage and the individual's own violent behaviour (Silver, 2002).

\section{Background}

Criminal victimisation of those with severe mental illness has been associated with more severe clinical symptoms (Brekke et al, 2001; Hiday et al, 2002), substance misuse (Hiday et al, 1999; Brekke et al, 2001), transient living conditions (including homelessness) (Hiday et al, 1999), lower functioning, lack of social support and a history of previous victimisation (Hiday et al, 2002). However, most studies examining associated factors have failed to distinguish between being the victim of a violent or a non-violent crime. Only one study to date has examined sociodemographic and clinical correlates of violent victimisation separately; this study found that one-third of patients discharged from psychiatric hospitals and living in hostels had been the victims of crime in the preceding year. Victims of violence were younger, more socially active, reported more psychopathology and less satisfaction with their lives and engaged in more criminal behaviour than both nonvictims and the victims of non-violent crime (Lehman \& Linn, 1984).

The aims of the present study are twofold: to establish the 1-year prevalence of violent victimisation in communitydwelling patients with psychosis and to compare this with the official statistics concerning prevalence in the general population; and to examine the sociodemographic and clinical correlates of violent victimisation in the largest sample of patients with psychosis to date.

\section{METHOD}

\section{Subjects}

A total of 708 subjects were recruited from four inner-city areas in England as part of the UK700 case management trial (UK700 Group, 1999). Subjects were identified by systematic review of in-patient and outpatient registers and fulfilled the following inclusion/exclusion criteria:

(a) aged 18-65 years;

(b) a diagnosis of psychosis: defined as the presence, according to Research Diagnostic Criteria (RDC; Spitzer et al, 1978), of delusions, hallucinations or thought disorder;

(c) hospitalised for psychotic symptoms at least twice, with the most recent admission within the past 2 years;

(d) absence of a primary diagnosis of substance misuse;

(e) absence of organic brain damage.

In this way, we set out to collect a sample of patients with established illness typical of those receiving multi-disciplinary psychiatric care in the community.

\section{Data collection}

All subjects were interviewed between 1994 and 1996 using a battery of instruments; these baseline assessments provided the data that were analysed for the purposes of this study. The interviewers were either senior trainee psychiatrists or psychology graduates, all of whom participated in an initial 2-day training course and completed five pilot interview schedules. Training materials included lectures, joint patient interviews, case vignettes and video interviews. Completed interview schedules were inspected regularly on site for errors and inconsistencies (UK700 Group, 1999).

as Editor of the Journal. 


\section{Outcome variables}

The primary outcome of interest was violent victimisation in the year prior to interview. As part of the Lancashire Quality of Life Profile (Oliver, 1991), subjects were asked the following question: 'In the last year have you been assaulted, beaten, molested or otherwise the victim of violence?' Respondents answered 'yes' or 'no' to this question. Perceived vulnerability to victimisation was measured by asking how satisfied subjects were with their own personal safety and the safety of their neighbourhood. Responses, scored on a seven-point Likert scale, were categorised into a binary outcome of satisfied/ dissatisfied.

\section{Explanatory variables}

Possible correlates of violent victimisation, chosen a priori on the basis of previous research, were measured using the following instruments.

(a) UK700 Socio-demographic Schedule: age, gender, ethnicity (interviewerassigned as White, African-Caribbean or Other), marital status, social class (by occupation of father at birth), educational achievement, age at onset and at first admission for psychosis and length of illness.

(b) Comprehensive Psychopathological Rating Scale (CPRS; Åsberg et al, 1978): measures the reported and observed psychopathology in the previous week.

(c) Scale for the Assessment of Negative Symptoms (SANS; Andreasen, 1984): an observer-rated measure of negative symptoms.

(d) Disability Assessment Scale (DAS; Jablensky et al, 1980): measures the level of disability.

(e) Camberwell Assessment of Need Research version (CAN-R; Phelan et al, 1995): a measure of the total number of 'unmet' needs for care.

(f) WHO Life Chart (World Health Organization, 1992a): information collected relates to the previous 2 years and includes homelessness, number of psychiatric admissions, months living independently and physical assault (self-report).

(g) Substance Misuse Questionnaire: subjects were asked about their use of alcohol and illegal drugs in the previous year; variables collected included alcohol misuse (greater than 2 units of alcohol per day for women and 3 units per day for men) and illegal drug use (coded as none, at least one and more than one).

(h) Operational Criteria Checklist for Psychotic Illness (OCCPI; McGuffin et al, 1991): used to generate RDC diagnoses from case notes.

(i) Personality Assessment Schedule, Rapid version (PAS-R; van Horn et al, 2000): derived from the original PAS schedule (Tyrer et al, 1979), the PAS-R is a direct development of the PAS and allows for a rapid screen for the presence of ICD-10 (World Health Organization, 1992b) personality disorder. Scoring for each category of personality disorder on the PAS-R is on a threepoint scale from 0 to $2(0$, absence of any dysfunction associated with the personality trait; 1 , personality difficulty; 2, personality disorder). For the purposes of this study, the PAS-R data were regrouped into a dichotomous variable with two categories: personality disorder and no personality disorder. (Personality disorder was defined as a PAS-R score of 2 on any personality disorder category.)

(j) Mental Illness Needs Index (MINI; Glover et al, 1998): this is based on postcode, designed to predict the number of people likely to receive inpatient care in a defined area, derived from socio-demographic variables (social isolation, poverty, unemployment, permanent sickness and temporary and insecure housing); it is used to adjust for deprivation of area of residence.

(k) Lancashire Quality of Life Profile (LQoLP; Oliver, 1991): apart from the primary outcome, this questionnaire also measured intensity of family contact.

(1) Offenders Index: a computerised database that holds criminal history data for more than six million offenders since 1963 in England and Wales. For the purposes of this study, criminal convictions were divided into violent and non-violent. The offence categories considered to constitute violence and listed under 'violence against the person' were murder, attempted murder, threat or conspiracy to murder, wounding or other act endangering life, assault, common assault, intimidation and molestation, and violent disorder. Non-violent offences included all other recorded offences. Official criminal records were sought for all subjects, who were subsequently coded as being either positive or negative for violent and non-violent offences.

\section{Statistical analysis}

The proportion of subjects reporting violent victimisation and perceived threat of victimisation was estimated. Possible socio-demographic and clinical correlates of violent victimisation were examined using logistic regression. Initially, the association between violent victimisation and each explanatory variable was examined unadjusted for other variables. All variables in the univariate analysis significant at $P=0.05$ were then entered into a multivariate model and stepwise methods were used to identify the final model best associated with violent victimisation. All other variables then were added to this final model to check that no significant correlates were missed. The final model was adjusted for age and gender. All analyses were conducted using STATA 6.0 (StataCorp, 1999).

\section{RESULTS}

\section{Recruitment}

Of those approached, $80 \% \quad(708 / 892)$ agreed to participate, $13 \%$ refused and a further $7 \%$ were not interviewed for a variety of reasons, including inability to establish contact. No significant differences were found between participants and nonparticipants in terms of basic demographic and clinical characteristics. However, compared with non-participants, patients who entered the trial had been ill for longer (median duration 120 months $v$. 96 months; $U=51899.0 ; P=0.04$ )

The demographic and clinical characteristics of the UK700 study profile have been described elsewhere (Burns et al, 1999). Tables 1 and 2 list these according to the victim profile. In the sample, more than half of the patients were young men with long histories of illness (median of 10 years; median of 2 months in hospital in the preceding 2 years). Most were diagnosed with schizoaffective disorder and schizophrenia. Nearly one-third of patients were African-Caribbean. Mean CPRS and DAS scores indicated that patients were moderately to severely ill. 
Table I Socio-demographic characteristics of the UK700 sample, by victim status

\begin{tabular}{|c|c|c|c|}
\hline \multirow[t]{2}{*}{ Variable } & \multicolumn{2}{|c|}{ Victim } & \multirow{2}{*}{$\begin{array}{l}\text { Odds ratio (95\% } \\
\mathrm{Cl} \text {, unadjusted) }\end{array}$} \\
\hline & $\begin{array}{c}\text { Yes } \\
(n=I I I)\end{array}$ & $\begin{array}{c}\text { No } \\
(n=580)\end{array}$ & \\
\hline \multicolumn{4}{|l|}{ Age, $n(\%)$} \\
\hline $18-39$ years & $84(20 \%)$ & $338(80 \%)$ & $2.32(1.45-3.71)^{* * *}$ \\
\hline $40-64$ years & $26(10 \%)$ & $243(90 \%)$ & 1 \\
\hline \multicolumn{4}{|l|}{ Gender, $n$ (\%) } \\
\hline Female & 37 (I2\%) & 257 (88\%) & 1 \\
\hline Male & 73 (18\%) & $324(82 \%)$ & $1.56(1.02-2.40)^{*}$ \\
\hline \multicolumn{4}{|l|}{ Ethnicity, $n$ (\%) } \\
\hline White & $61(17 \%)$ & 297 (83\%) & 1 \\
\hline African-Caribbean & 30 (16\%) & 161 (84\%) & $0.68(0.56-1.46)$ \\
\hline Other & $19(13 \%)$ & $123(13 \%)$ & 0.31 (0.43-I.3I) \\
\hline \multicolumn{4}{|l|}{ Marital status, $n$ (\%) } \\
\hline Ever married & $32(14 \%)$ & 205 (86\%) & 1 \\
\hline Single & 78 (17\%) & $376(83 \%)$ & $1.32(0.85-2.07)$ \\
\hline \multicolumn{4}{|c|}{ Occupation of father at birth, $n(\%)$} \\
\hline Non-manual & 15 (18\%) & $69(82 \%)$ & $\mathrm{I}$ \\
\hline Manual & $52(16 \%)$ & $282(84 \%)$ & $0.84(0.45-1.59)$ \\
\hline Unemployed & $22(15 \%)$ & 127 (85\%) & $0.79(0.38-1.63)$ \\
\hline \multicolumn{4}{|l|}{ Employed (past 2 years), $n$ (\%) } \\
\hline No & $88(16 \%)$ & $456(84 \%)$ & $\mathrm{I}$ \\
\hline Yes & $22(15 \%)$ & $125(85 \%)$ & $0.72(0.54-I .5 I)$ \\
\hline \multicolumn{4}{|l|}{ Homeless (past 2 years), $n$ (\%) } \\
\hline No & $96(15 \%)$ & 555 (82\%) & 1 \\
\hline Yes & $14(35 \%)$ & $26(65 \%)$ & $3.12(1.56-6.17)^{* * *}$ \\
\hline \multicolumn{4}{|l|}{ Family contact (past year), $n(\%)$} \\
\hline Daily & 31 (12\%) & $234(88 \%)$ & $\mathrm{I}$ \\
\hline Less than daily & $76(18 \%)$ & $342(82 \%)$ & $1.67(1.07-2.62)^{*}$ \\
\hline Independent living, mean (s.d.) & $15(8)$ & $17(8)$ & $0.97(0.95-0.99)^{*}$ \\
\hline \multicolumn{4}{|l|}{ Assault (past 2 years), $n$ (\%) } \\
\hline No & $76(13 \%)$ & $493(87 \%)$ & 1 \\
\hline Yes & $33(28 \%)$ & 84 (72\%) & $2.54(1.59-4.07)^{* * *}$ \\
\hline \multicolumn{4}{|l|}{ Violent conviction, $n(\%)$} \\
\hline No & $78(14 \%)$ & $487(86 \%)$ & 1 \\
\hline Yes & $32(25 \%)$ & 94 (75\%) & $2.13(1.33-3.39)^{* *}$ \\
\hline \multicolumn{4}{|l|}{ Non-violent conviction, $n$ (\%) } \\
\hline No & $62(13 \%)$ & $40 \mathrm{I}(87 \%)$ & 1 \\
\hline Yes & $48(21 \%)$ & $180(79 \%)$ & $1.72(1.13-2.61)^{* *}$ \\
\hline MINI score, mean (s.d.) & $442(72)$ & $440(63)$ & $1.00(0.99-1.00)$ \\
\hline
\end{tabular}

MINI, Mental IIlness Needs Index.

$* P<0.05 ; * * P<0.01 ; * * * P<0.001$

Prevalence of violent victimisation Information on victimisation was available for $691(98 \%)$ of the subjects at interview; $111(16 \%)$ reported being a victim of violence in the previous year. With regard to perceived threat, $269 / 678(40 \%)$ were dissatisfied with their personal safety and $301 / 677$ (44\%) were dissatisfied with the safety of their neighbourhood. Victims were significantly more likely to report feeling personally unsafe $(n=65,58 \%$; $P<0.001)$ and unsafe in their neighbourhood $(n=66,59 \% ; P<0.001)$ than nonvictims. Our interviews were conducted between 1994 and 1996. For comparison, crime figures collected at that time for the British Crime Survey reveal an annual percentage of victimisation for contact crime of $6.7 \%$ in London and $7.1 \%$ for all inner cities. The figure for non-inner-city areas was $4.9 \%$ (Murless-Black et al, 1996).

\section{Characteristics of victims: univariate analysis}

The socio-demographic characteristics of subjects reporting victimisation are presented in Table 1. Compared with nonvictims, victims were significantly more likely to be male, under 40 years and with transient living conditions, including homelessness. Victims were less likely to have daily contact with their families and spent less time in independent accommodation in the community compared with nonvictims. Victims were more likely to have had contact with the law, with significantly more criminal convictions for violent and non-violent crime and more recent selfreported violent behaviour. There was no significant association between being a victim of violence and being a member of an ethnic minority group, recent employment or degree of deprivation of area of residence.

The clinical characteristics of subjects reporting victimisation are presented in Table 2. Although those with early illness onset, higher scores on general psychopathology and more unmet needs for care were more likely to be victims, the length of illness, level of negative symptoms and disability were not associated with victim status. Compared with non-victims, victims also were more likely to have a comorbid personality disorder. With regard to substance misuse, victims used significantly more illegal drugs but were not more likely to misuse alcohol. Those using one illegal drug were almost two and a half times more likely to be victimised and those using two or more such drugs were over four times more likely to be victims of violence than those denying any use.

\section{Assessment of independent effects using multivariate analysis}

Table 3 presents the final multivariate model identifying the associations between each variable and victim status, adjusted for age, gender and each other. Being homeless $(P=0.01)$, using illegal drugs $(P<0.001)$, being the perpetrator of an assault $(P=0.01)$, having greater current symptomatology $(P=0.02)$ and a comorbid 
Table 2 Clinical characteristics of the UK700 sample, by victim status

\begin{tabular}{|c|c|c|c|}
\hline \multirow[t]{2}{*}{ Baseline risk factor } & \multicolumn{2}{|c|}{ Victim } & \multirow{2}{*}{$\begin{array}{l}\text { Odds ratio } \\
(95 \% \mathrm{Cl})\end{array}$} \\
\hline & $\begin{array}{c}\text { Yes } \\
(n=I I I)\end{array}$ & $\begin{array}{c}\text { No } \\
(n=580)\end{array}$ & \\
\hline \multicolumn{4}{|l|}{ Diagnosis, $n$ (\%) } \\
\hline Schizoaffective disorder & $54(16 \%)$ & $283(84 \%)$ & 1 \\
\hline Schizophrenia & $44(17 \%)$ & $221(83 \%)$ & $1.04(0.67-1.61)$ \\
\hline Affective psychosis & $8(17 \%)$ & $40(83 \%)$ & $1.04(0.46-2.36)$ \\
\hline Other psychoses & $4(10 \%)$ & 37 (90\%) & $0.56(0.19-1.65)$ \\
\hline \multicolumn{4}{|c|}{ Comorbid personality disorder, $n$ (\%) } \\
\hline No & $57(12 \%)$ & $416(88 \%)$ & 1 \\
\hline Yes & $46(25 \%)$ & 137 (75\%) & $2.45(1.58-3.78)$ \\
\hline Age at onset (years), mean (s.d.) & $23(7)$ & $26(8)$ & $0.96(0.93-0.99)^{* *}$ \\
\hline Time ill (months), mean (s.d.) & $136(110)$ & $151(117)$ & $0.99(0.99-1.00)$ \\
\hline CPRS total, mean (s.d.) & $23(14)$ & $18(12)$ & $1.02(1.01-1.04)^{* *}$ \\
\hline SANS, mean (s.d.) & $22(16)$ & $21(16)$ & $1.02(0.99-1.01)$ \\
\hline DAS total, mean (s.d.) & $1.22(0.78)$ & $1.13(0.86)$ & $\mathrm{I} .12(0.88-\mathrm{I} .4 \mathrm{I})$ \\
\hline \multicolumn{4}{|l|}{ Hospital admissions, $n$ (\%) } \\
\hline Less than two & 37 (12\%) & $416(88 \%)$ & 1 \\
\hline Two or more & $73(19 \%)$ & I37 (75\%) & $1.87(1.21-2.85)^{* *}$ \\
\hline Unmet needs, mean (s.d.) & $3.15(2.7)$ & $2.5(2.3)$ & $1.11(1.02-1.21)^{* *}$ \\
\hline \multicolumn{4}{|l|}{ Drug use/misuse (past year), $n$ (\%) } \\
\hline None & $65(12 \%)$ & $468(88 \%)$ & I \\
\hline One & $27(24 \%)$ & $83(75 \%)$ & $2.34(1.4 I-3.88)$ \\
\hline Two or more & $18(38 \%)$ & $30(62 \%)$ & $4.32(2.27-8.18)^{* *}$ \\
\hline \multicolumn{4}{|l|}{ Alcohol, $n(\%)$} \\
\hline$<2-3$ units/day & 93 (I5\%) & 535 (85\%) & I \\
\hline$>2-3$ units/day & II (24\%) & 35 (76\%) & $1.81(0.88-3.68)$ \\
\hline
\end{tabular}

CPRS, Comprehensive Psychopathological Rating Scale; DAS, Disability Assessment Scale; SANS, Scale for the Assessment of Negative Ssymptoms.

$* * P<0.01$.

personality disorder $(P=0.006)$ were all independently associated with being a victim of violence.

\section{DISCUSSION}

Sixteen per cent of 691 patients living in the community reported being the victim of violence over 1 year, a figure that is more than twice that recorded from general population figures in the UK during the same period. Compared with non-victims, victims of violence were significantly more likely to report more severe psychopathological symptoms, to have been homeless, to have misused drugs, to admit to having assaulted another person and to suffer from a comorbid personality disorder.

\section{Strengths and weaknesses of the study}

This is the largest study to date to examine the prevalence and correlates of violent
Table 3 Socio-demographic and clinical correlates of violent victimisation

\begin{tabular}{|c|c|}
\hline Factor & $\begin{array}{l}\text { Odds ratio } \\
(95 \% \mathrm{Cl})^{1}\end{array}$ \\
\hline \multicolumn{2}{|c|}{ Homeless (past 2 years) } \\
\hline Yes & $2.67(1.23-5.77)^{* *}$ \\
\hline \multicolumn{2}{|c|}{ Assault (past 2 years) } \\
\hline Yes & $2.08(1.18-3.43)^{* *}$ \\
\hline \multicolumn{2}{|c|}{ Comorbid personality disorder } \\
\hline Yes & $1.93(1.20-3.10)^{* *}$ \\
\hline \multicolumn{2}{|c|}{ CPRS total (mean) } \\
\hline Victim & $1.02(1.00-1.04)^{*}$ \\
\hline \multicolumn{2}{|c|}{ Drug use/misuse (past year) } \\
\hline None & I \\
\hline One & $1.76(1.01-3.09)$ \\
\hline Two or more & $3.81(1.87-7.77)^{* * *}$ \\
\hline
\end{tabular}

victimisation rather than predictive factors. We are therefore cautious about drawing inferences concerning causation based on these data.

The UK700 study did not employ a general population or non-psychotic control sample with whom we could compare the prevalence of victimisation. We thus chose to rely on official records for comparison, which were collected in a different way and for different purposes. There is evidence to suggest that individuals with mental illnesses are more likely to be assaulted by people with whom they have a close relationship (Cascardi et al, 1996). It is therefore likely that victimisation will be underreported for various reasons, including protection of the perpetrator, shame and guilt, reluctance to discuss unpleasant memories and fear of future violence. The comparative figures for the general population derive from anonymous interviews with members of the public and are therefore less susceptible to underreporting. Despite this, the difference in the prevalence of violent victimisation is still impressive. We did not include nonviolent victimisation, emotional abuse or social exploitation in our definition.

\section{Prevalence of violent victimisation}

Sixteen per cent of our subjects reported having been the victims of violence in the previous year. Because information was missing for 17 patients, the highest possible 
prevalence for victimisation in the sample was $18 \%$, assuming that all those missing had been victimised, and the lowest prevalence was $16 \%$, assuming that they had not. This gives a prevalence range of $16-$ $18 \%$, a figure more than twice that recorded in the general population at that time, according to the British Crime Survey. This prevalence figure is higher than that reported in the USA. Hiday et al (2002) reported that $10 \%$ of persons with severe mental illness who had been deemed suitable for enforced community treatment post-discharge were victimised in the first year. The comparative national rate was $3.1 \%$. In an earlier study of the same patients the 4-month period prevalence of victimisation was $8.2 \%$, suggesting that the annual prevalence rate would be somewhat higher. Brekke et al (2001) followed 172 patients in the community for 3 years to assess their vulnerability to risk and reported that $34 \%$ of their sample were victims of violence over this period, presenting an annual risk closer to ours. Silver (2002), in a case-control study, compared the prevalence of violent victimisation among 270 recently discharged people with severe mental illness over 10 weeks post-discharge with 477 neighbourhood controls. Using data from the Pittsburgh site of the McArthur Risk Assessment Study, he found that significantly more patients $(15 \%)$ than neighbourhood controls $(7 \%)$ reported violent victimisation. Certain factors have been found to increase the risk of victimisation in the general population, including male gender, younger age, unemployment and ethnic minority status. Despite controls being derived from the same neighbourhood, patients still possessed more of these factors. Following statistical adjustment for these and for the individual's own violence perpetration, patients were still nearly twice as likely to be violently victimised than controls.

\section{Factors associated with violent victimisation}

Our finding that victims of violence display more severe clinical symptoms is consistent with previously published literature on the subject (Lehman \& Linn, 1984; Brekke et al, 2001; Hiday et al, 2002). Homelessness (Hiday et al, 1999), substance misuse (Hiday et al, 1999; Brekke et al, 2001) and a history of violence (Lehman \& Linn, 1984) were also identified as significantly related to victimisation, as in previous work. However, it is difficult to make valid comparisons with other studies because researchers have either grouped non-violent victimisation together as a single outcome (Hiday et al, 1999, 2002) or they have used highly heterogeneous samples of patients.

Our results show that victims were more likely to misuse illegal substances, to have a recent history of assaulting others and to be diagnosed with a comorbid personality disorder, all of which have been shown previously to increase the risk for violent behaviour in the sample (Walsh $e t$ al, 2001; Moran et al, 2003). Victimisation also has been found independently to predict violence in the sample (Walsh et al, 2001). Childhood abuse and neglect are risk factors for adult mental illness and have been shown to have a significant impact on the likelihood of delinquency, adult criminality and violence (Maxfield \& Widom, 1996; Hiday et al, 2001). Those with psychosis are more likely to be born in cities (Marcelis et al, 1998), and social drift (Goldberg \& Morrison, 1963) makes them more likely to live in socially disorganised and crime-ridden neighbourhoods and be subjected to violence (Hiday et al, 2001). Our results show that those who have been victimised were significantly more likely to feel threatened and unsafe than others and consequently it is more likely that they will engage in violence themselves. It is therefore conceivable that victimisation and violence in severe mental illness share a common pathway and that the occurrence of one or both outcomes will be determined by complex interactions between these factors across the life cycle. It should be noted, however, that less than half of victims reported committing an assault in the 2 years before interview, indicating that an individual's own violence may only explain a proportion of violent victimisation in the sample. Furthermore, the link between severe mental illness and violent victimisation has been shown recently to be independent of an individual's own tendency towards violence (Silver, 2002).

Compliance with treatment was not measured in this study, but all subjects were in contact with services, suggesting that patients at particular risk of victimisation could be targeted for more assertive follow-up. One such assertive approach, called out-patient commitment, is practised in certain states in North America, where it has been shown to reduce significantly criminal victimisation in people with severe mental illnesses (Hiday et al, 2002). Within this approach, patients are ordered by law to receive treatment and supervision by a named treatment provider.

\section{Implications of the study}

It is becoming increasingly clear that there is a need to refocus the issue of community risk away from the danger posed by mentally ill individuals to the danger posed to them from other members of society (Walsh $\&$ Fahy, 2002). This has been highlighted by an American finding that patients with psychosis living in the community are 14 times more likely to be the victims of a violent crime than to be arrested for such a crime (Brekke et al, 2001). Further longitudinal work is needed to clarify the predictors of victimisation, which may be used to target vulnerable subgroups with additional care. Enquiry about victimisation experiences does not form part of the routine psychiatric interview. In light of our findings and other emerging evidence on the size of the victimisation problem among people with mental illnesses, we suggest that such enquiry be incorporated as standard.

\section{ACKNOWLEDGEMENTS}

E.W. was funded by a Wellcome Training Fellowship. The UK700 trial was funded by grants from the UK Department of Health and an NHS research and development programme.

The UK700 Group is a collaborative study team involving four clinical and two non-clinical centres: Manchester Royal Infirmary: Tom Butler, Francis Creed, Janelle Fraser, Peter Huxley, Nicholas Tarrier, Theresa Tattan. King's/Maudsley Hospital, London: Tom Fahy, Catherine Gilvarry, Kwame McKenzie, Robin Murray, Jim van Os, Elizabeth Walsh. St Mary's Hospital/St Charles' Hospital, London: John Green, Anna Higgitt, Elizabeth van Horn, Donal Leddy, Catherine Manley, Patricia Thornton, Peter Tyrer. St George's Hospital, London: Robert Bale, Tom Burns, Matthew Fiander, Kate Harvey, Andy Kent, Chiara Samele. Centre for Health Economics, York: Sarah Byford, David Torgerson, Ken Wright. London (Statistics): Simon Thompson (Royal Postgraduate Medical School) and lan White (London School of Hygiene and Tropical Medicine).

\section{REFERENCES}

Åsberg, M., Montgomery, S. A., Perris, C., et al (1978) A comprehensive psychopathological rating scale. Acta Psychiatrica Scandinavica Supplementum, 27I, 5-27.

Andreasen, N. C. (1984) Modified Scale for the Assessment of Negative Symptoms. lowa City, IA: University of lowa.

Brekke, J. S., Prindle, C., Woo Bae, S., et al (200I) Risks for individuals with schizophrenia who are living in the community. Psychiatric Services, 52, 1358-1366. 
Burns, T., Creed, F., Fahy, T., et al (1999) Intensive versus standard case management for severe psychotic illness: a randomised trial. UK700 Group. Lancet, 353 2185-2189.

Cascardi, M., Mueser, K.T., DeGiralomo, J., et al (1996) Physical aggression against psychiatric inpatients by family members and partners. Psychiatric Services, 47 531-533.

Glover, G. R., Robin, E., Emami, J., et al (1998) A needs index for mental health care. Social Psychiatry and Psychiatric Epidemiology, 33, 89-96.

Goldberg, E. M. \& Morrison, S. L. (1963)

Schizophrenia and social class. British Journal of Psychiatry, 109, 785-802.

Hiday, V. A., Swanson, J.W., Swartz, M. S., et al (1999) Criminal victimisation of persons with severe mental illness. Psychiatric Services, 50, 62-68.

_, _, _, et al (200I) Victimization: a link between mental illness and violence? International Journal of Law and Psychiatry, 24, 559-572.

_ , Swartz, M. S., Swanson, J.W., et al (2002) Impact of outpatient commitment on victimisation of people with severe mental illness. American Journal of Psychiatry, 8, |403-|4||.

Jablensky, A., Schwartz, R. \& Tomov, T. (1980) WHO collaborative study of impairments and disabilities associated with schizophrenic disorders: a preliminary communication - objectives and methods. Acto Psychiatrica Scandinavica, 62, 152-163.

Lehman, A. F. \& Linn, L. S. (1984) Crimes against discharged mental patients in board-and-care homes. American Journal of Psychiatry, 14I, 27I-274.

Marcelis, M., Navarro-Mateu, F., Murray, R., et al (1998) Urbanization and psychosis: a study of 1942-1978 birth cohorts inThe Netherlands. Psychological Medicine, 4, 87I-879.

Maxfield, M. G. \& Widom, C. (1996) Cycle of violence revisited 6 years later. Archives of Pediatrics and Adolescent Medicine, 150, 390-395.

\section{McGuffin, P., Farmer, A. \& Harvey, I. (1991) A} polydiagnostic application of operational criteria in studies of psychotic illness. Development and reliability of the OPCRIT system. Archives of General Psychiatry, 48 764-770

Moran, P., Walsh, E., Tyrer, P., et al (2003) Impact of comorbid personality disorder on violence in psychosis. Report from the UK700 trial. British Journal of Psychiatry, 182, 129-134.

Mullen, P. E., Burgess, P., Wallace, C., et al (2000) Community care and criminal offending in schizophrenia. Lancet, 355, 614-617.

Murless-Black, C., Mayhew, P. \& Percy, A. (1996) British Crime Survey 1996. London: Home Office.

Oliver, J. (1991) The social care directive: development of a quality of life profile for use in community services for the mentally ill. Social Work and Social Sciences Review, 3, 53-60.

Phelan, M., Slade, M., Thornicroft, G., et al (1995) The Camberwell Assessment of Need: the validity and

\section{CLINICAL IMPLICATIONS}

- Violent victimisation of patients with psychosis is a significant problem: $16 \%$ were violently victimised over I year.

- Those at particular risk of victimisation have more severe symptoms and poorer social circumstances.

- Assertive enforced community treatment, which has been shown to reduce victimisation in the USA, needs further evaluation in other settings.

\section{LIMITATIONS}

- The study was conducted in inner cities, so the findings are not generalisable to other settings.

- It is a cross-sectional study that identified correlates rather than predictors of victimisation.

- General population figures are used for comparison, rather than other controls.

ELIZABETH WALSH, MD, PAUL MORAN, MD, Institute of Psychiatry, London; CHARLES SCOTT, MD, University of California, Davis, CA, USA; KWAME McKENZIE, MRCPsych, Royal Free School of Medicine, London; TOM BURNS, MD, St George's Hospital Medical School, London; FRANCIS CREED, MD, University Department of Psychiatry, Manchester Royal Infirmary, Manchester; PETER TYRER, MD, St Mary's Hospital Medical School, London; ROBIN M. MURRAY, MD, TOM FAHY, MD, Institute of Psychiatry, London

Correspondence: Dr Elizabeth Walsh, Section of Forensic Mental Health, The Institute of Psychiatry, De Crespigny Park, Denmark Hill, London SE5 8AF, UK. E-mail: sppmemw@iop.kcl.ac.uk

(First received I2 February 2003, final revision 19 May 2003, accepted 21 May 2003)

reliability of an instrument to assess the needs of people with severe mental illness. British Journal of Psychiatry, 167, 589-595.

Silver, E. (2002) Mental disorder and violent victimization: the mediating role of involvement in conflicted social relationships. Criminology, 40, |9|-21।.

Spitzer, R., Endicott, J. \& Robins, E. (1978) Research Diagnostic Criteria: rationale and reliability. Archives of General Psychiatry, 35, 773-782.

StataCorp (1999) Stata Statistical Software, Release 6.0. College Station, TX: Stata Corporation.

Tyrer, P., Alexander, M. S., Cicchetti, D, et al (1979) Reliability of a schedule for rating personality disorders. British Journal of Psychiatry, 135, 168-174.

UK700 Group (1999) Comparison of intensive and standard case management for patients with psychosis. Rationale of the trial. British Journal of Psychiatry, 174, 74-78.
Van Horn, E., Manley, C., Leddy, D., et al (2000) Problems in developing an instrument for the rapid assessment of personality status. European Psychiatry, 16 (suppl. I). 29-33.

Walsh, E. \& Fahy, T. (2002) Violence in society contribution of mental illness. BMJ, 325, 507-508.

_ , Gilvarry, C., Samele, C., et al (200I) Reducing violence in severe mental illness: randomised controlled trial of intensive case management compared with standard care. BMI, 323, 1093-1096.

_ , Buchanan, A. \& Fahy, T. (2002) Violence and schizophrenia: examining the evidence. British Journal of Psychiatry, I8I, 490-495.

World Health Organization (1992a) The Life Chart. Geneva: WHO

- (1992b) The ICD-10 Classification of Mental and Behavioural Disorders. Geneva: WHO. 